\title{
Acute Generalized Exanthematous Pustulosis Induced by Cefepime: A Case Report
}

\author{
L.F.F. Botelho ${ }^{a}$ F.R. Picosse ${ }^{a} \quad$ M.H. Padilha ${ }^{a} \quad$ N. Michalany ${ }^{b}$ \\ A. Góis ${ }^{c}$ A.M. Porro ${ }^{\mathrm{a}}$ \\ Departments of a Dermatology, ${ }^{\mathrm{b}}$ Anatomopathology, and ${ }^{\mathrm{C} E m e r g e n c y ~ M e d i c i n e, ~}$ \\ Federal University of São Paulo, São Paulo, Brazil
}

\section{Key Words}

Acute generalized exanthematous pustulosis - Drug eruption - Cefepime

\begin{abstract}
Acute generalized exanthematous pustulosis (AGEP) is a rare cutaneous rash characterized by widespread sterile nonfollicular pustules. Cefepime is a fourth generation cephalosporin, used to treat severe infections. A 67-year-old man was admitted with acute gastroenterocolitis. On the seventh day, the patient developed a nosocomial pneumonia and cefepime was initiated. On the fourth day of cephalosporin treatment, he presented with a maculopapular, pruritic eruption affecting the face, neck, abdomen and limbs. One day later he developed disseminated pustular lesions and his temperature was $37^{\circ} \mathrm{C}$. Laboratory analysis evidenced leukocytosis and skin biopsy showed subcorneal pustule, edema in the papillary dermis, perivascular inflammatory infiltrate consisting of neutrophils, leukocytoclasia and red cell extravasation in the epidermis. Cefepime was suspended and within 4 days the non-follicular pustules cleared following a desquamation. AGEP is a disease attributed to a variety of causes, but in $90 \%$ of the cases it is due to an adverse drug reaction. Antibiotics are implicated in $80 \%$ of these cases, mostly penicillins and macrolides. There are few cases associated with cephalosporins. It is very important to consider AGEP in cases of acute pustular rashes and drugs should be investigated as causative agents.
\end{abstract}

\section{Introduction}

Acute generalized exanthematous pustulosis (AGEP) is a rare acute reaction that is drug-induced in $90 \%$ of the cases [1], characterized by a widespread, sterile pustular rash. Pustules resolve spontaneously within a few days. 
Cefepime is a fourth generation cephalosporin antibiotic used to treat febrile neutropenia, severe infections related to the urinary tract, skin, nosocomial pneumonia, brain abscess, and intra-abdominal and septic lateral/cavernous sinus thrombosis [2].

\section{Case Report}

A 67-year-old man with renal failure who had been on dialysis during the last 2 years and with an 8 -year history of cardiac insufficiency was admitted to the hospital complaining of 6 days of diarrhea. He was hypotensive and dehydrated at admission. The patient was taken to the semi-intensive care unit and treated with ciprofloxacin. As a consequence, his diarrhea resolved on the sixth day after admission. His long-term medications had not been changed and consisted of acetylsalicylic acid, furosemide, captopril, carvedilol and clonazepam. On the seventh day, the patient became dyspneic and his chest radiograph showed a left lower lobe opacity. Treatment for nosocomial pneumonia was promptly initiated with cefepime (1 g/day). Five days later, he presented with a pruritic, erythematous, maculopapular eruption affecting the abdomen, neck and skin folds. One day later, he developed disseminated pustular lesions (fig. 1) and his temperature was $37^{\circ} \mathrm{C}$. Laboratory exams evidenced C-reactive protein $136 \mathrm{mg} / \mathrm{l}$, white blood cells 14,700 cells/ $\mu \mathrm{l}$ (normal 3,500-10,500 cells/ $\mu \mathrm{l}$ ) with 11,995 cells/ $\mu$ l neutrophils (normal 1,700-8,000 cells/ $\mu \mathrm{l}$ ). Histology showed a toxic pustuloderma with spongiform subcorneal pustules, edema in the papillary dermis and perivascular inflammatory infiltrate consisting of neutrophils (fig. 2). Leukocytoclasis and red cell extravasation in the epidermis were present. After withdrawal of cefepime and introduction of imipenem, the disseminated skin nonfollicular pustules cleared within 4 days following a desquamation. The patient denied previous adverse reaction to other drugs and no personal or family history of psoriasis was evident. He was discharged from the hospital on day 19 after admission.

\section{Discussion}

AGEP is a disease characterized by the rapid onset of many sterile, nonfollicular pustules usually arising on an edematous erythema and frequently accompanied by leukocytosis and fever. Skin symptoms usually arise rapidly after an insult and resolve spontaneously (within a few days). AGEP often starts predominantly in intertriginous areas or on the face, spreading rapidly to the trunk and lower limbs. The mean duration of the pustules is 9.7 days, and an annular desquamation typically follows for a few days. Complications are rare $[1,3]$. The AGEP validation score of the EuroSCAR study group has been used to establish the diagnosis [4]. A score between 8 and 12 for AGEP is a definitive diagnosis (table 1). The case score was 11, according to the validation score of the EuroSCAR study group (table 2).

The main differential diagnosis of AGEP is pustular psoriasis. Because the pustules clinically and histologically resemble the lesions of pustular psoriasis and because in a number of reports patients had a history of plaque psoriasis, some authors assume that AGEP is nothing more than an acute exacerbation of psoriasis caused by a variety of exogenous triggers. However, many studies strongly suggest that AGEP is not associated with psoriasis $[1,5]$.

Up to now AGEP has been attributed to a variety of causes such as viral infections [610], Chlamydia pneumoniae infection [11] or hypersensitivity to mercury [12], but the skin reaction is primarily an adverse response to drugs. Antibiotics, other than cefepime, have been implicated as the causative agents in $80 \%$ of individuals [13]. In this group, the disease is usually caused by penicillins or macrolides [14, 15]. The present case of AGEP has well defined criteria, and because correct diagnosis generally leads to spontaneous resolution once the causative drug is withdrawn, clinicians should keep the possibility of this cutaneous drug reaction in mind. 
Table 1. AGEP validation score of EuroSCAR study group

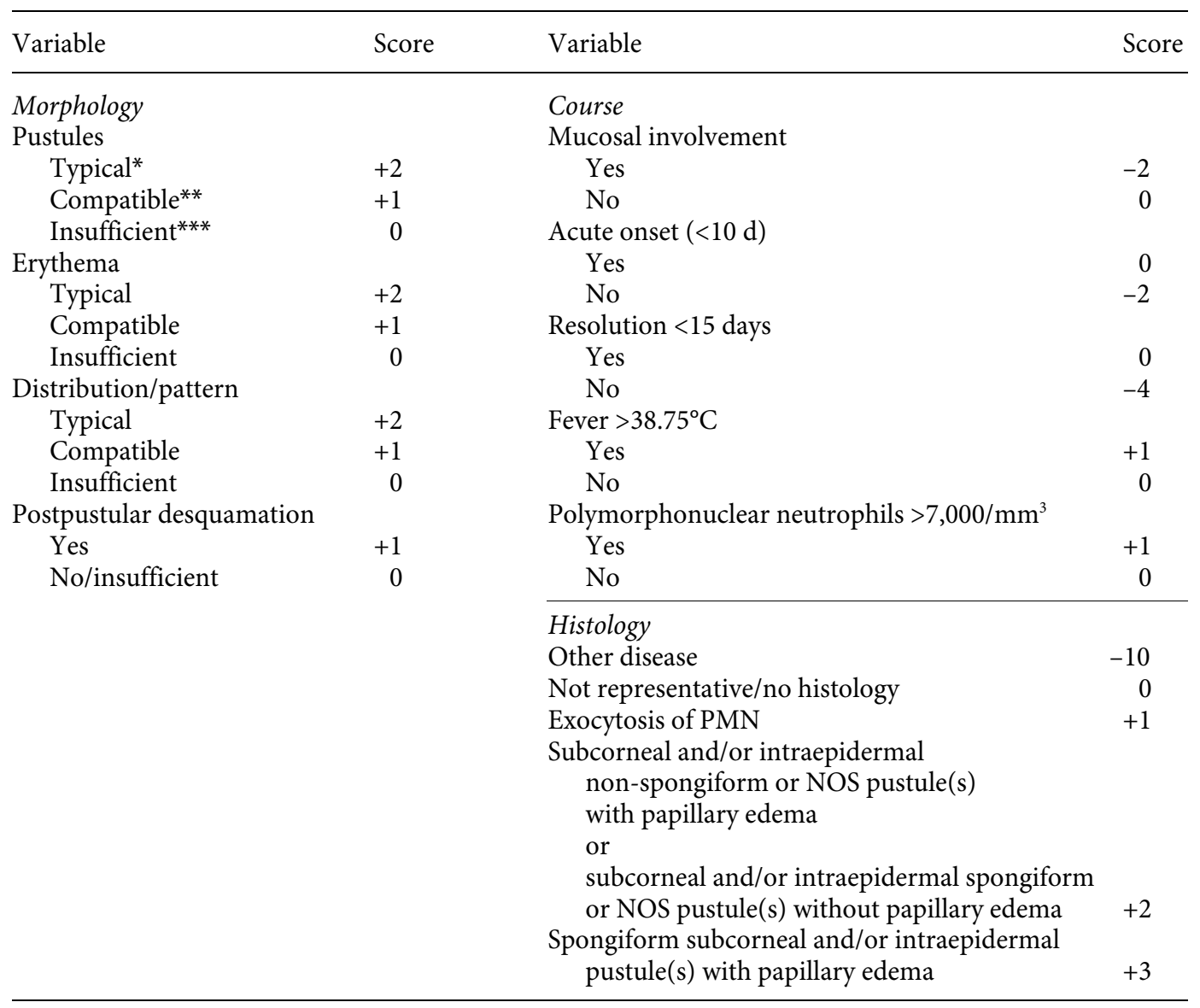

NOS = not otherwise specified.

Interpretation: $\leq 0$ : no AGEP; 1-4: possible; 5-7: probable; 8-12: definite.

* Typical: typical morphology.

** Compatible: not typical, but not strongly suggestive of other disease.

*** Insufficient: lesions cannot be judged. 
Table 2. Patient AGEP score, according to EuroSCAR study group

\begin{tabular}{|c|c|}
\hline Variable & Score \\
\hline \multicolumn{2}{|l|}{ Morphology } \\
\hline \multicolumn{2}{|l|}{ Pustules } \\
\hline Typical & +2 \\
\hline \multicolumn{2}{|l|}{ Erythema } \\
\hline Typical & +2 \\
\hline \multicolumn{2}{|l|}{ Distribution/pattern } \\
\hline Typical & +2 \\
\hline \multicolumn{2}{|l|}{ Postpustular desquamation } \\
\hline Yes & +1 \\
\hline \multicolumn{2}{|l|}{ Course } \\
\hline \multicolumn{2}{|l|}{ Mucosal involvement } \\
\hline No & 0 \\
\hline \multicolumn{2}{|l|}{ Acute onset (<10 days) } \\
\hline Yes & 0 \\
\hline \multicolumn{2}{|l|}{ Resolution $<15$ days } \\
\hline Yes & 0 \\
\hline \multicolumn{2}{|l|}{ Fever $>38.75^{\circ} \mathrm{C}$} \\
\hline \multirow{2}{*}{\multicolumn{2}{|c|}{$\begin{array}{l}\text { No } \\
\text { Polymorphonuclear neutrophils }>7,000 / \mathrm{mm}^{3}\end{array}$}} \\
\hline & \\
\hline Yes & +1 \\
\hline \multicolumn{2}{|l|}{ Histology } \\
\hline $\begin{array}{l}\text { Spongiform subcorneal and/or intraepidermal } \\
\text { pustule(s) with papillary edema }\end{array}$ & +3 \\
\hline
\end{tabular}

Fig. 1. Pustular lesions affecting the neck.

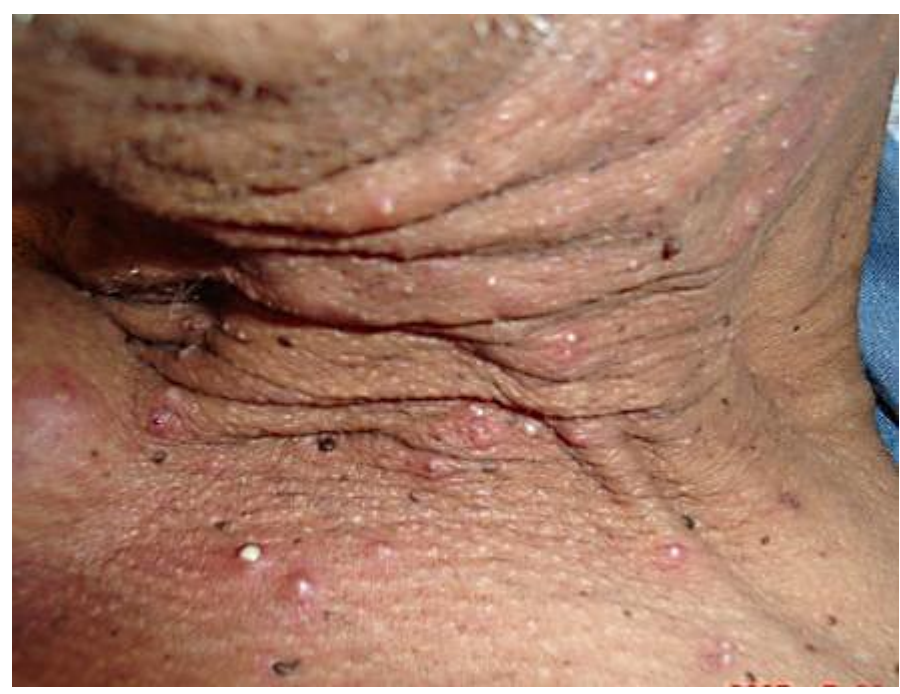


Fig. 2. Histology showed a toxic pustuloderma with spongiform subcorneal pustule and perivascular inflammatory infiltrate consisting of neutrophils.

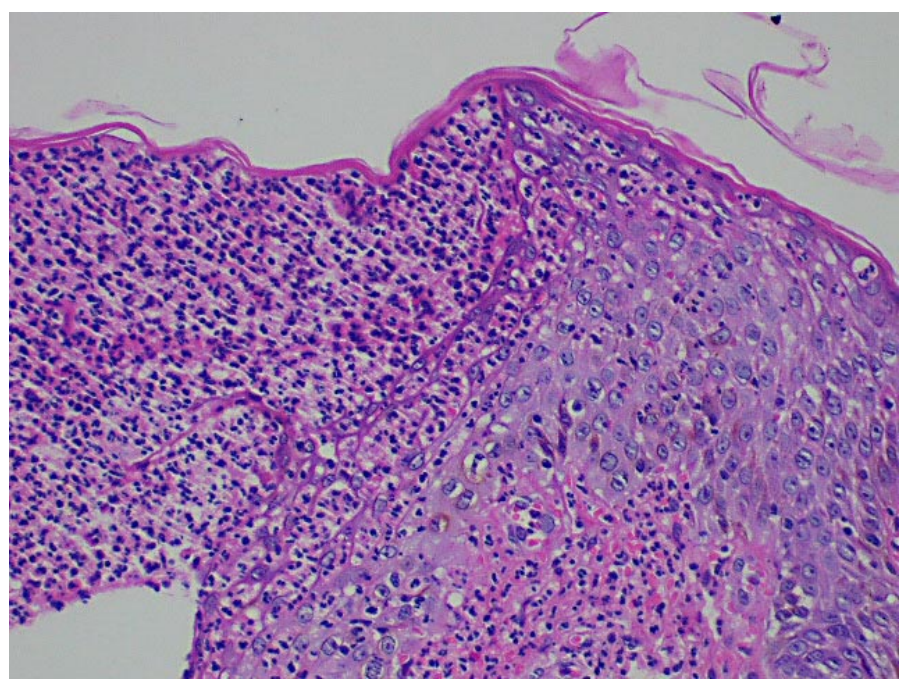




\section{References}

1 Sidoroff A, Dunant A, Viboud C, Halevy S, Bavinck JN, Naldi L, Mockenhaupt M, Fagot JP, Roujeau JC: Risk factors for acute generalized exanthematous pustulosis (AGEP) - results of a multinational case-control study (EuroSCAR). Br J Dermatol 2007;157:989-996.

-2 Barradell LB, Bryson HM: Cefepime. A review of its antibacterial activity, pharmacokinetic properties and therapeutic use. Drugs 1994;47:471-505.

-3 Beylot C, Doutre MS, Beylot-Barry M: Acute generalized exanthematous pustulosis. Semin Cutan Med Surg 1996;15:244-249.

-4 Sidoroff A, Halevy S, Bavinck JN, Vaillant L, Roujeau JC: Acute generalized exanthematous pustulosis (AGEP) - a clinical reaction pattern. J Cutan Pathol 2001;28:113-119.

5 Spencer JM, Silvers DN, Grossman ME: Pustular eruption after drug exposure: is it pustular psoriasis or a pustular drug eruption? Br J Dermatol 1994;130:514-519.

6 Ofuji S, Yamamoto O: Acute generalized exanthematous pustulosis associated with a human parvovirus B19 infection. J Dermatol 2007;34:121-123.

7 Rouchouse B, Bonnefoy M, Pallot B, et al: Acute generalized exanthematous pustular dermatitis and viral infection. Dermatologica 1986;173:180-184.

8 Feio AB, Apetato M, Costa MM, et al: Acute generalized exanthematous pustulosis due to Coxsackie B4 virus (in Portuguese). Acta Med Port 1997;10:487-491.

9 Haro-Gabaldon V, Sanchez-Sanchez-Vizcaino J, Ruiz-Avila P, et al: Acute generalized exanthematous pustulosis with cytomegalovirus infection. Int $J$ Dermatol 1996;35:735-737.

10 Naides SJ, Piette W, Veach LA, et al: Human parvovirus B19-induced vesiculopustular skin eruption. Am J Med 1988;84:968-972.

11 Manzano S, Guggisberg D, Hammann C, et al: Acute generalized exanthematous pustulosis: first case associated with a Chlamydia pneumoniae infection (in French). Arch Pediatr 2006;13:1230-1232.

12 Lerch M, Bircher AJ: Systemically induced allergic exanthem from mercury. Contact Derm 2004;50:349-353.

13 Roujeau JC, Bioulac-Sage P, Bourseau C, et al: Acute generalized exanthematous pustulosis. Analysis of 63 cases. Arch Dermatol 1991;127:1333-1338.

14 Manders SM, Heymann WR: Acute generalized exanthemic pustulosis. Cutis 1994;54:194-196.

15 Trevisi P, Patrizi A, Neri I, Farina P: Toxic pustuloderma associated with azithromycin. Clin Exp Dermatol 1994;19:280-281. 